\title{
International Meeting of Anatomia Clinica \& International Symposium of Clinical and Applied Anatomy (ISCAA), 24th to 26th June 2019, Madrid, Spain
}

Anatomy 2018;12(3):159 @2018 Turkish Society of Anatomy and Clinical Anatomy (TSACA)

Dear colleagues,

We are happy to announce that Abstract Submission and Registration to the International Meeting of Anatomia Clinica (European Association of Clinical Anatomist, EACA) and the International Symposium of Clinical and Applied Anatomy (ISCAA), which will take place from 24th to 26th June 2019 in Madrid (Spain) is now open.

Visit www.eaca2019.com to get an account which will allow you to submit abstracts, register to the meeting.

Deadline for receipt of abstracts - 11 April 2019

The accepted abstracts will be published in the Surgical and Radiologic Anatomy journal.
We look forward to meeting you all in Madrid, June 2019 for an enjoyable Meeting!

Sincerely,

Prof. Jose Sanudo

President of the Congress

Department of Human Anatomy \& Embryology,

Faculty of Medicine,

Complutense Universtiy of Madrid

Av. Ciudad Universitaria s/n 28040-Madrid. Spain.

Tel: +34 913941381

e-mail: jrsanudo@ucm.es 